\title{
Adolescents' Triangulation in Marital Conflict and Peer Relations
}

By: Cheryl Buehler, Karen L. Franck, Emily C. Cook

This is the accepted version of the following article:

Buehler, C., Franck, K. L., \& Cook, E. C. (2009). Adolescents' triangulation in marital conflict and peer relations. Journal of Research on Adolescence 19(4), 669-689.,

which has been published in final form at http://dx.doi.org/10.1111/i.15327795.2009.00616.x.

\section{***(C) Society for Research on Adolescence \& Wiley. Reprinted with permission. No further reproduction is authorized without written permission from Wiley. This version of the document is not the version of record. Figures and/or pictures may be missing from this format of the document. $* * *$}

\begin{abstract}
:
This study examined the association between youths' triangulation in marital conflict and three aspects of their peer relations in 416 families during early adolescence. A 4-wave, longitudinal research design was used. As hypothesized, triangulation was associated negatively with perceived support from friends and positively with perceived peer rejection. Triangulation was a risk factor for both sons and daughters. Adolescent problem behavior did not mediate the significant association between triangulation and perceived friendship support. Adolescent problem behavior, particularly internalizing problems, completely me diated the association between triangulation and adolescents' perceptions of peer rejection, suggesting the important developmental role of adolescents' anxiety, depressive affect, and withdrawal. The implications of these findings are discussed in terms of Bowen's multigenerational family systems theory and social learning principles.
\end{abstract}

Keywords: Adolescents | Family | Marital conflict | Peer relations | Triangulation | Problem behavior

\section{Article:}

Family socialization processes shape relations with peers (Kerns, Contreras, \& Neal-Barnett, 2000). One important domain in two-parent families is marital relations (Parke et al., 2001), and a salient risk factor within this domain is youths' triangulation in parents' marital disputes (Grych, Raynor, \& Fosco, 2004). Triangulation is a system process in which a child is involved in parents' conflictual interactions (Bowen, 1978; Minuchin, 1974). As part of the triangulation process, children often feel caught in the middle or torn between parents (Buchanan, Maccoby, \& Dornbusch, 1991). Theoretically, triangulation is an important socialization variable because it constitutes boundary violations that create emotional distress and model dysfunctional ways of 
addressing interpersonal conflicts and tensions (Amato \& Afifi, 2006; Bowen, 1978). In addition to these direct effects, we also propose that triangulation affects adolescents' peer relations over time through adolescents' behavior problems (Bosco, Renk, Dinger, Epstein, \& Phares, 2003) because youth socioemotional difficulties might decrease peer support and increase the likelihood of peer rejection.

This study tested a prospective model of family influences on early adolescent peer relations that suggests two patterns: (a) triangulation in parents' marital conflict negatively affects adolescents' perceptions of peer relationships, and (b) adolescents' socioemotional problems partially mediate the association between triangulation and adolescents' perceptions of peer relations. These hypotheses were examined in a sample of 416 two-parent families. Four yearly assessments were conducted, beginning when youth were in sixth grade. Three aspects of adolescents' perceptions of peer relations were examined: best friend support, general peer support, and peer rejection.

\section{BACKGROUND}

\section{Theoretical Foundation}

The model tested in this study was developed by integrating concepts and propositions from three theoretical frameworks: multigenerational family systems theory (Bowen, 1978), social learning theory (Parke et al., 2001), and Capaldi's developmentally oriented, social learning model of family process (Capaldi \& Crosby, 1997). First, multigenerational family systems theory contends that triangulation places children and adolescents at risk for psychological and social problems (Bowen, 1978; Kerr \& Bowen, 1988). In his review, Charles (2007) defined triangulation as a family system-level construct in which "two people in a family bring in a third party to dissolve stress, anxiety, or tension that exists between them” (p. 281). In the current study, we focus on one central aspect of triangulation in families: offspring's involvement in marital tension and conflict. Westerman (1987) noted that although theorists differentially emphasize various manifestations of this type of triangulation, such as the formation of parentchild coalitions or blaming a child for parents' marital problems, most scholars agree that an essential defining characteristic of triangulation is that offspring are caught in the middle of parents. Thus, most conceptualizations of triangulation into marital conflict include a focus on triadic relationships (in addition to the resulting dyadic coalitions that are formed and maintained) and the contention that these triadic patterns linking marital and parent-child dyads signify boundary violations in which children are caught between parents (Afifi, 2003; Anderson \& Fleming, 2003; Benson, Larson, Wilson, \& Demo, 1993; Margolin, Gordis, \& Richard, 2001).

Theoretically, triangulation into parents' marital conflicts compromises adolescents' mental health and their social relationships with close friends and romantic partners (Benson et al., 1993). In particular, triangulation places adolescents at risk for relational problems with agemates because youth are placed in untenable and confusing family relationships (Bowen, 1978). When adolescents are triangulated during parents' disagreements, youth are exposed to elevated 
levels of parental anxiety, irritation, and anger. By definition, they also are involved in parents' conflict interactions, typically as mediators or allies. In theory, involvement helps reduce parents' anxiety, promoting youths' continued triangulation in parental disagreements (Bowen, 1978).

Over time, youth learn to involve others in dyadic disputes rather than dealing with the disagreements directly and learn dysfunctional ways of interacting with intimates. This pattern of addressing relationship tension creates difficulties in balancing intimacy and autonomy issues within close relationships, potentially decreasing intimacy in close friendships and increasing withdrawal and rejection by age-mates (Kerr \& Bowen, 1988).

The second informative theoretical perspective for the current study was social learning. Social learning principles suggest direct associations between triangulation into parental disputes and difficulties with friendships during adolescence (Markiewicz, Doyle, \& Brengdon, 2001). This learning occurs both through the observation of parents' interactions with one another (i.e., observational learning) and through participatory experiences as an ally, mediator, or distractor (i.e., interactional learning). For example, as part of a family triangle focused on parental disputes, youth might learn to meet intimacy needs by using manipulation and coercion. This process forecasts transmission from family to peers and supports the hypothesis that offsprings' triangulation into marital conflict is associated negatively with adolescents' relationship quality (e.g., lower support) with age-mates over time (Conger, Cui, Bryant, \& Elder, 2000).

Capaldi's theoretical integration of a developmentally oriented family process framework and social learning principles also informed the proposed model (Capaldi \& Clark, 1998; Capaldi \& Crosby, 1997; Capaldi \& Stoolmiller, 1999). She proposed that over time family processes (ineffective parenting in particular) negatively affect the quality of adolescents' social relationships over time by shaping general socioemotional maladjustment, including adolescents' externalizing and internalizing problems. This theoretical proposition is incorporated into the model tested in the current study by including adolescents' problem behaviors as a partial mediator of the prospective association between adolescents' triangulation into parental disputes and their peer relationships. We extend Capaldi's theoretical formulations regarding family influences by focusing on marital relations rather than parenting.

\section{Empirical Foundation}

Triangulation and adolescents' peer relations. We propose that triangulation into marital conflict impairs peer relationships. To our knowledge, no study has examined the affects of triangulation on peer relationships during middle adolescence. However, Dunn, Davies, O'Connor, and Sturgess (2001) investigated the concurrent association between involvement in marital conflict (i.e., triangulation) on friendships in a sample of younger children living in single, step, and nondivorced families. Triangulation in two-parent families was associated negatively with friendship quality (but not in single-parent families). Research focused on marital hostility (rather than triangulation) also has found links between marital relations and social skills with age-mates (Markiewicz et al., 2001; O'Neil, Parke, Flyr, \& Wild, 1999). For 
example, marital hostility has been associated with adolescents' aggressive conflict tactics with close friends (Cantrell, MacIntyre, Sharkey, \& Thompson, 1995). Thus, although theoretically compelling, the empirical literature on the association between adolescents' triangulation into parental disputes and the quality of peer relations is sparse. The current study addresses this gap by examining the proposition that triangulation is associated negatively with adolescents' perceptions of peer relationships over time during the first half of adolescence.

The moderating role of youth gender. The moderating effects of youth gender were not examined in any of the reviewed studies on triangulation but should be considered because adolescent daughters might be more vulnerable to the deleterious relational effects of parents' marital triangulation ( Jacobvitz \& Bush, 1996). Although not limited to triangulation, a recent study by Davies and Lindsay (2004)supports the need to examine the moderating effects of youth gender. Using a measure of marital conflict that combined frequency, intensity, resolution, content, and child involvement, they found that the association between marital conflict and adolescent internalizing problems was stronger for daughters than for sons. They also found that about three-fourths of this differential effect was accounted for by daughters' higher levels of communion toward others. In the current study, we build on these findings by examining the hypothesis that the association between adolescents' triangulation into parents' marital conflict is associated with peer relations more strongly for daughters than for sons.

The mediating role of adolescents' problem behaviors. We also extend the current literature by examining the proposition that adolescents' problem behaviors partially mediate the association between triangulation and adolescents' perceptions of peer relations. Triangulation has been associated with both externalizing (Amato \& Afifi, 2006) and internalizing problems (Jacobvitz \& Bush, 1996; Wang \& Crane, 2001). Kerig (2001) suggested that externalizing or internalizing behaviors might represent misguided strategies to modify one's feelings and emotions about marital conflict, supporting the hypothesis that adolescents' problem behaviors partially link triangulation in marital conflict and the quality of adolescents' peer relations.

In terms of the second half of the proposed mediating pathway, youth who express higher levels of aggression and display anxious behaviors might have difficulty developing high quality peer relationships (Crick \& Grotpeter, 1995; Ladd \& Burgess, 1999). Accordingly, adolescents' externalizing behavior has been associated with peer rejection and impaired friendships (Bagwell \& Coie, 2003; Parker \& Asher, 1987). Furthermore, children who report internalizing problems also have been more likely to experience peer rejection (Hay, Payne, \& Chadwick, 2004; Hymel, Rubin, Rowden, \& LeMare, 1990).

The unique function of triangulation. Theoretically and empirically, adolescents' triangulation in the marital relationship occurs within the context of marital conflict (Bowen, 1978; Margolin et al., 2001). Research that has included measures of both marital conflict and adolescents' triangulation has documented that triangulation has unique associations with adolescent problem behaviors and socioemotional well-being (Amato \& Afifi, 2006; Bosco et al., 2003; Grych et al., 
2004). Thus, marital hostility was included in the analyses as a control variable so that the unique processes associated with triangulation could be isolated.

\section{Hypotheses}

Based on these theoretical and empirical literatures, two sets of hypotheses were tested as modeled in Figure 1:

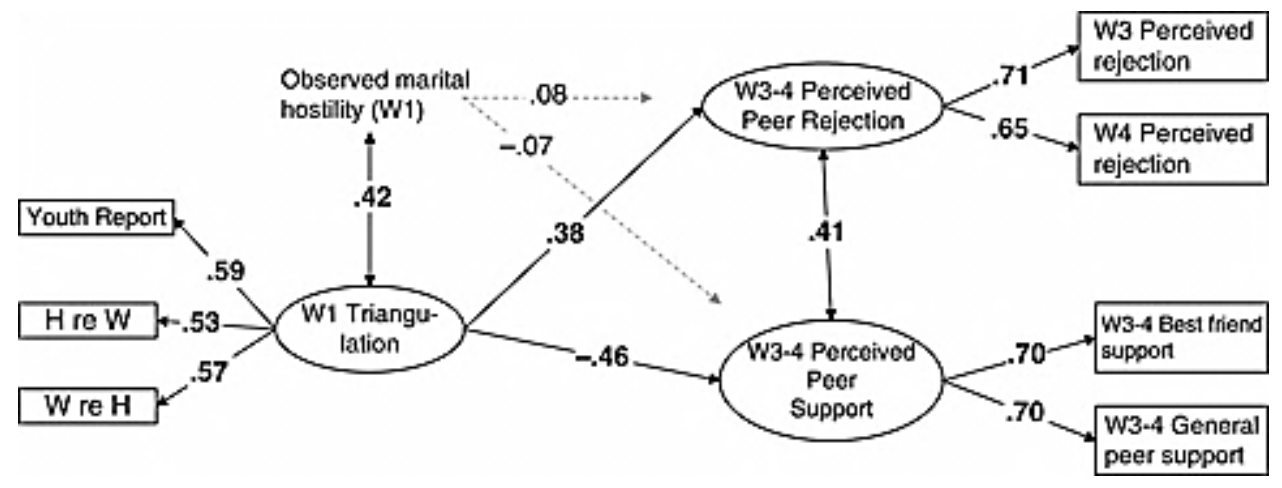

Figure 1. Youths' triangulation in marital conflict and perceived peer support and rejection.

1 Early adolescents' triangulation in marital disputes is associated prospectively with adolescents' perceptions of peer relationships and status. Specifically, triangulation is associated negatively with perceived peer support and close friend support. Triangulation also is associated positively with perceived rejection by peers. Although significant for both genders, these associations are stronger for daughters than for sons.

2 The prospective association between adolescents' triangulation in marital disputes and perceived peer relations is mediated partially by adolescents' socioemotional difficulties (both externalizing problems and internalizing problems).

\section{METHOD}

\section{Sampling Procedures and Characteristics}

The sample was taken from a larger study of the effects of family life on the transition from childhood into adolescence. For the larger study, sixth grade youth in 13 middle schools in a large, geographically diverse county in the southeastern United States were invited to participate. Children in sixth grade were selected because they are beginning the transition from childhood into adolescence. Ninety-six percent of the teachers participated. Youth received a letter during homeroom inviting their participation. Two additional invitations were mailed directly to parents. About $71 \%$ of the youth/parent(s) returned the consent form and $80 \%$ of these youth received parental permission to complete a questionnaire on family life during school. This resulted in a sample of 2,346 sixth grade youth. The sample was representative of families in the 
county on race, parents' marital status, and family poverty status (contact the author for details using county census information).

Families for the present study were recruited from the larger sample of youth using the following criteria: parents were married or long-term cohabitants and there were no stepchildren in or out of the home $(n=1,131)$. Stepfamilies were not included for three reasons: (a) stepfamilies have complex structures that differ from ever-married families and a careful study would need to include adequate sample sizes of these various structures to conduct group comparisons; (b) data would need to be collected regarding birth parent-child relations as well as stepparent-child relations in order to understand the findings accurately; and (c) funds were inadequate to collect data from both stepparents and nonresidential birth parents.

Four hundred and sixteen parents participated in the current study (36\% response rate). Primary reasons given for nonparticipation included time constraints and/or an unwillingness for one or more family members to be videotaped. This response rate was similar to that in studies that have included three or four family members and have used intensive data collection protocols (e.g., National Survey of Families and Hoseholds-34\%; Updegraff et al., 2004-37\%). Using information from the initial youth survey for selection analyses, eligible participating families were similar to eligible nonparticipating families on all study variables (contact author for statistical details). These findings suggested minimal selection bias into the two-parent sample used for the present study.

At wave 1 (W1) when youth were in the sixth grade, they ranged in age from 11 to 14 $(M=11.86, S D=.69)$. There were 211 daughters (51\%). In terms of race, $91 \%$ of the families were European American. The average level of parents' education in this sample was an associate's degree (2 years of college). Parents' educational attainment was similar to that of European American adults in the county who were older than 24 (county mean category was some college, no degree; U.S. Census, 2000b, Table P148A of SF4). The median level of 2001 household income for families in this study was about US\$70,000, which was higher than the median 1999 income for married-couple families in the county (US\$59,548, U.S. Census, 2000a, Table PCT40 of SF3; US\$64,689 inflation-adjusted dollars through 2001).

\section{Data Collection Procedures}

Youth completed a questionnaire during school. They had as much time as needed to finish, and several trained assistants and the study director were available to answer questions. Family members were mailed a questionnaire and asked to complete it independently. The completed, sealed questionnaires were collected during a home visit. Parents and youth completed a second questionnaire during the home visit. This second questionnaire contained the most sensitive information (e.g., youths' delinquent behavior), and a researcher's presence ensured privacy.

Data for the control variable of marital hostility were collected during an in-home observation at W1. Family members participated in two observational tasks during the home visit that were 
videotaped and coded later by trained observers. The first was a 20-min problem-solving activity and mother, father, and youth participated. Each person completed the Issues Checklist before the interaction task (Conger, Conger, \& Elder, 1992), and based on this information, the home visitors selected several salient topics. Participants were asked to elaborate the issue, identify who usually is involved, and suggest possible solutions. The second 20-min task included only the wife and husband and focused on the marital relationship, daily interaction patterns, and coparenting. Within each participating family, different coders rated the interaction from the two tasks to minimize coder carryover effects.

As part of the longitudinal research design, home visits were conducted again to collect data a year later (W2; $N=366$ ), 2 years later (W3; $N=340$ ), and 3 years later (W4; $N=322$ ). Thus, there were four assessments, each conducted a year apart. Most youth were 14 or 15 years old when W4 data were collected. Attrition analyses using MANOVA were conducted using the W1 data and there were no differences between families who stayed and left on any of the study variables, suggesting minimal attrition bias (contact author for statistical details). Families were paid for their participation each year: US $\$ 100$ for W1, US $\$ 115$ for W2, US $\$ 130$ for W3, and US $\$ 150$ for W4.

\section{Assessment Plan}

In the absence of an experimental research design, theoretical models that include mediational pathways are best tested using longitudinal data so that the exogenous, mediating, and endogenous variables can be assessed at different time points (Shadish, Cook, \& Campbell, 2002). In the current study, triangulation was the exogenous variable and was assessed at W1. Adolescents' problem behavior was the mediating variable and was assessed at W2 (a year later). Adolescents' perceived peer relationships were the endogenous variables and were assessed at W3 and W4 (2 and 3 years after W1). Given there were four waves of data available in the larger study, two assessments of perceived peer relations were included in the current study so that the focus was on somewhat stable relationship patterns with peers in general and with close friends (Dishion, Eddy, Haas, Li, \& Spracklen, 1997). The control variable of marital hostility was assessed at W1 because it was included to capture the context of triangulation, which also was assessed at W1.

\section{Measurement}

Triangulation. Conceptualized and operationalized as a unidimensional construct that involves offspring in parents' marital conflicts, triangulation can manifest in several behavioral and perceptual ways. For example, one parent and a child might side together against the other parent (Charles, 2007; West, Zarski, \& Harvill, 1986). This type of alliance formation includes youths' perceptions of feeling loyalty conflicts toward parents (Amato \& Afifi, 2006), feeling compelled to take sides (Benson et al., 1993), and feeling caught in the middle or torn between parents (Grych, Seid, \& Fincham, 1992). This pattern of triangulation was operationalized in the current 
study using parents' reports of their spouses' siding behaviors and youths' perceptions of parental requests for an ally and feeling caught in the middle. Another form of triangulation is one parent complaining to the offspring about the other parent. These complaints can take the form of descriptions, criticisms, and insults (Grych et al., 1992; Margolin et al., 2001). This form of triangulation was operationalized in the current study using parent and youth reports of one parent saying insulting, cruel, or hurtful things to the child about the other parent. Triangulation also manifests by parents blaming or "scapegoating” offspring for their marital difficulties (Anderson \& Fleming, 2003). This model of triangulation was operationalized in the current study using parents' reports of their spouses' blaming children for marital conflict. Finally, triangulation manifests when offspring form a communication pathway between parents, carrying messages or eliciting information from one parent to give to the other parent (Buchanan et al., 1991; Grych et al., 1992). This pattern of triangulation was operationalized in the current study using youth and parent reports of the child as a communication link. Although offsprings' triangulation into marital conflict can take various forms, researchers have found that measures of these various patterns form a unidimensional measure of triangulation (Amato \& Afifi, 2006; Benson et al., 1993; Grych et al., 1992; Jacobvitz \& Bush, 1996; Margolin et al., 2001).

Accordingly, in the present study, youth and parents completed questionnaire measures of triangulation into parental disputes at W1. The youth measure had 7 items -2 items from the Children's Perceptions of Interparental Conflict scale (CPICi; Grych et al., 1992) and the 5-item Covert Conflict Scale developed by Buehler et al. (1998). Sample items were "How often do you feel caught in the middle when your parents fight?" and "How often does one of your parents try to get you to side with one of them.” The response scale ranged from 1 (never) to 4 (very often). Items were averaged and a high score indicated more triangulation $(\alpha=.79)$. Bradford et al. (2004) provided evidence of construct validity of the measure in 11 samples from eight countries. The parent measure had 13 items that were adapted/extracted from three existing measures (CPIC, Grych et al., 1992; Conflict and Problem Solving scale, Kerig, 1996; Coparenting Questionnaire, Margolin et al., 2001). Sample items were: "How often does your spouse talk with this child about conflict with you?" and "How often does your spouse involve this child in disagreements between you and your spouse?” The response scale ranged from 1 (never) to 5 (always). Items were averaged and a high score indicated more triangulation (husband about wife $\alpha=.84$; wife about husband $\alpha=.82$ ).

Perceived peer relations. Three aspects of perceived peer relations at W3 and W4 were measured: best/close friend support, general peer support, and peer rejection. Youth completed a 7-item measure of close friend support (Vernberg, Abwender, Ewell, \& Beery, 1992). They were asked to think of a same-sex best friend when responding to the questions. Sample items were "If you needed help with something, how often could you count on this friend to help you?” and "How often do you tell this friend things about yourself that you wouldn't tell most kids?" The response scale ranged from 1 (never) to 5 (every day). Items were averaged and a high score indicated more support (W3 $\alpha=.78$; W4 $\alpha=.81$ ). Youth also completed a 5-item measure of 
perceived peer support (Bowen, Wooley, \& Richman, 2001). Sample items were "I can count on my friends for support" and "I am able to tell my problems to my friends.” The response scale ranged from 1 (not like me) to 3 (a lot like me). Items were averaged and a high score indicated more support (W3 $\alpha=.80$; W4 $\alpha=.86$ ). The third measure of peer relations was a single-item regarding perceived peer rejection. Youth were asked to respond to the item "I am disliked or rejected by other kids.” The response scale ranged from 1 (strongly disagree) to 4 (strongly agree). The correlation between W3 and W4 responses was .47 $(p<.001)$.

Adolescents' problem behaviors. Problems behaviors at W2 were measured using youth selfreports and parent reports. Youth completed the Youth Self-Report Form (Achenbach, 1991). Parents completed the parallel Child Behavior Checklist (Achenbach, 1991). Examples of externalizing items include: "lying or cheating” and "scream a lot." The response format was 0 (not true), 1 (somewhat or sometimes true), and 2 (very true or often true). Thirty-three items measured externalizing problems (W2 $\alpha$ for youth, mothers, fathers $=.90, .87, .89$, respectively). Thirty-one items measured internalizing problems (W2 $\alpha$ for youth, mothers, fathers $=.90, .85$, .85 , respectively). Examples of internalizing items include: "feel worthless or inferior" and "feel too fearful or anxious.” For each reporter, the internalizing and externalizing scores were summed to create a total measure of adolescent problem behaviors.

Marital hostility. Marital hostility was measured using observer ratings to minimize shared method bias between the measures of hostility and triangulation. Trained coders rated wife's behavior toward husband and husband's behavior toward wife during the two interaction tasks. The following scales were used from the Iowa Family Interaction Rating Scales: hostility, angry coercion, verbal attack, and antisocial (Melby et al., 1993). Verbal attack includes critical, demeaning, global comments that transcend specific situations. Angry coercion includes control attempts that are hostile in nature. Hostility is a composite scale that includes situationally specific criticisms and sarcasm. Antisocial is a composite negativity rating that also includes uncooperativeness and rudeness. In addition, two rating scales were developed for this study: personal attack and yelling. Personal attack includes global criticisms that are directed toward the partner's character. Yelling includes intense, expressed negative affect. Behavior is rated using a 1 (not present) to 9 (mostly characteristic) response format. Cronbach's $\alpha$ was .85 for the observed rating composite. Twenty percent of the tasks were selected randomly to be coded by a second coder and the average agreement across raters was .79. Interrater reliability was assessed by calculating single-item intraclass correlation coefficients (ICCs) based on a one-way random effects ANOVA (Melby \& Conger, 2001). The average ICC for this composite measure was .51, which is adequate for these rating scales and comparable with other studies that have used IFIRS ratings (Melby \& Conger).

\section{Analytic Design and Method}

Data were analyzed using structural equation modeling (AMOS 6) and the probability level for statistical significance was set at .05. The latent construct of triangulation into parents' marital 
conflict was measured at W1 (youth sixth grade) using three manifest variables: youth reports, husband reports of wife, and wife reports of husband. The latent construct of perceived best friend support was measured using two manifest measures: youth reports at W3 and W4. The latent construct of perceived general peer support was measured using two manifest measures: youth reports at W3 and W4. The latent construct of perceived peer rejection was measured using two manifest measures: youth reports at W3 and W4. The latent construct of adolescent problem behavior was measured at W2 using three manifest variables: youth self-report of problem behaviors, mothers' reports of adolescent problem behaviors, and fathers' reports of adolescent problem behaviors.

Model fit was evaluated using the chi-square statistic and two fit indices. A nonsignificant chisquare indicated a good model fit. However, because of the large sample size, a significant chisquare was expected for most models and additional fit indices were examined (Byrne, 2001). Fit indices such as the CFI range from 0 to 1.00 with a cutoff of 0.95 or higher indicating a wellfitting model and 0.90 indicating an adequate fit (Hu \& Bentler, 1999). Values for the root mean square error of approximation (RMSEA) below .05 indicate a good model fit and between 06 and .08 indicate an adequate fit (Browne \& Cudeck, 1993). Missing data were treated using a full information maximum likelihood estimation procedure (FIML). FIML produces estimates that are less biased than do other procedures such as deleting cases with both cross-sectional and panel data (Acock, 2005; Newman, 2003).

\section{RESULTS}

The descriptive statistics are shown in the Table 1. Zero-order correlations were in the expected directions. Preliminary analyses were conducted using SEM to examine the associations between triangulation and each of the three aspects of peer relations. This was done in three separate analyses. The association between triangulation and perceived best friend support was negative and significant $(\beta=-.37, p<.001)$. Model fit was good, $\chi^{2}=6.08(4), p>.05$, CFI=.99, RMSEA $=.035$. The same pattern occurred for perceived general peer support $(\beta=-.39, p<.001)$. Model fit was adequate, $\chi^{2}=15.89(4), p=.003$, CFI=.94, RMSEA=.08. The association between triangulation and perceived peer rejection was positive and significant $(\beta=.42, p<.001)$. Model fit was good, $\chi^{2}=1.63(4), p>.05, \mathrm{CFI}=.99$, RMSEA=.01. These preliminary analyses suggested that the peer measures of best friend support and general friend support were not distinct latent constructs. Thus, the primary analyses were conducted using two latent constructs to measure peer relations. The first was perceived peer rejection and had two manifest indicators: W3 perceived rejection and W4 perceived rejection. The second was perceived peer support and had two manifest indicators: perceived best friend support and perceived general peer support. Each of these support manifest indicators was created by averaging the appropriate composite summary scores from W3 and W4. The latent constructs of perceived peer rejection and perceived peer support were related but distinct measures of peer relations (the association between disturbances was .41, $p<.001$ ) in the first analysis shown in Figure 1. 
Table 1. Triangulation in Marital Conflict, Adolescent Problem Behaviors, and Peer Relationships: Correlations and Descriptive Statistics

\begin{tabular}{|c|c|c|c|c|c|c|c|c|c|c|c|c|c|}
\hline Variables & 1 & 2 & 3 & 4 & 5 & 6 & 7 & 8 & 9 & 10 & 11 & 12 & 13 \\
\hline $\begin{array}{l}\text { 1. W1 } \\
\text { triangulation } \\
-\mathrm{YR}\end{array}$ & - & & & & & & & & & & & & \\
\hline $\begin{array}{l}\text { 2. W1 } \\
\text { triangulation } \\
\text {-FR }\end{array}$ & $0.28^{* *}$ & - & & & & & & & & & & & \\
\hline $\begin{array}{l}\text { 3. W1 } \\
\text { triangulation } \\
\text {-MR }\end{array}$ & $0.38^{* *}$ & $0.29^{* *}$ & - & & & & & & & & & & \\
\hline $\begin{array}{l}\text { 4. W2 } \\
\text { externalizing } \\
\text {-YR }\end{array}$ & $0.12^{*}$ & 0.06 & 0.06 & - & & & & & & & & & \\
\hline $\begin{array}{l}\text { 5. W2 } \\
\text { externalizing } \\
\text {-PR }\end{array}$ & 0.09 & $0.25^{* *}$ & $\begin{array}{l}0.17 \\
* *\end{array}$ & $0.42^{* *}$ & - & & & & & & & & \\
\hline $\begin{array}{l}\text { 6. W2 } \\
\text { internalizing } \\
-\mathrm{YR}\end{array}$ & $0.14^{* * *}$ & 0.05 & 0.02 & $0.66^{* *}$ & $0.21^{* * *}$ & - & & & & & & & \\
\hline $\begin{array}{l}\text { 7. W2 } \\
\text { internalizing } \\
\text {-PR }\end{array}$ & $0.15^{* *}$ & $0.24^{* *}$ & $\begin{array}{l}0.17 \\
* *\end{array}$ & $0.23^{* * *}$ & $0.50^{* *}$ & $\begin{array}{l}0.38^{*} \\
{ }_{*}^{*}\end{array}$ & - & & & & & & \\
\hline $\begin{array}{l}\text { 8. W3 BF } \\
\text { support- } \\
\text { YR }\end{array}$ & $\begin{array}{l}-0.16 \\
* *\end{array}$ & $\begin{array}{l}-0.20 \\
* * \\
* *\end{array}$ & $\begin{array}{l}-0.1 \\
0\end{array}$ & $\begin{array}{l}-0.15 \\
* * \\
* *\end{array}$ & $\begin{array}{l}-0.12 \\
*\end{array}$ & $\begin{array}{l}-0.0 \\
5\end{array}$ & $\begin{array}{l}-0.0 \\
9\end{array}$ & - & & & & & \\
\hline $\begin{array}{l}\text { 9. W4 BF } \\
\text { support- } \\
\text { YR }\end{array}$ & $\begin{array}{l}-0.14 \\
* *\end{array}$ & $\begin{array}{l}-0.19 \\
* * \\
* *\end{array}$ & $\begin{array}{l}-0.0 \\
8\end{array}$ & $\begin{array}{l}-0.16 \\
* *\end{array}$ & $\begin{array}{l}-0.19 \\
* *\end{array}$ & $\begin{array}{l}-0.1 \\
2^{*}\end{array}$ & $\begin{array}{l}-0.1 \\
1\end{array}$ & $0.49^{* *}$ & - & & & & \\
\hline $\begin{array}{l}\text { 10. W3 peer } \\
\text { support- } \\
\text { YR }\end{array}$ & $\begin{array}{l}-0.24 \\
* * \\
* *\end{array}$ & $\begin{array}{l}-0.22 \\
* * \\
* *\end{array}$ & $\begin{array}{l}-0.0 \\
4\end{array}$ & -0.08 & $\begin{array}{l}-0.16 \\
* *\end{array}$ & $\begin{array}{l}-0.0 \\
4\end{array}$ & $\begin{array}{l}-0.1 \\
3^{*}\end{array}$ & $0.37^{* *}$ & $0.26^{* *}$ & - & & & \\
\hline $\begin{array}{l}\text { 11. W4 peer } \\
\text { support- } \\
\text { YR }\end{array}$ & $\begin{array}{l}-0.17 \\
* *\end{array}$ & $\begin{array}{l}-0.13 \\
*\end{array}$ & $\begin{array}{l}-0.0 \\
4\end{array}$ & -0.04 & -0.09 & $\begin{array}{l}-0.0 \\
7\end{array}$ & $\begin{array}{l}-0.0 \\
6\end{array}$ & $0.32^{* *}$ & $0.46^{* *}$ & $0.44^{* *}$ & - & & \\
\hline $\begin{array}{l}\text { 12. W3 peer } \\
\text { rejection- } \\
\text { YR }\end{array}$ & $0.12^{*}$ & $0.14^{*}$ & $\begin{array}{l}0.11 \\
*\end{array}$ & $0.20^{* *}$ & $0.21^{* *}$ & $\begin{array}{l}0.29^{*} \\
{ }_{*}\end{array}$ & $\begin{array}{l}0.32^{*} \\
{ }^{*}\end{array}$ & $\begin{array}{l}-0.31 \\
* *\end{array}$ & $\begin{array}{l}-0.22 \\
* *\end{array}$ & $\begin{array}{l}-0.23 \\
* * \\
* *\end{array}$ & $\begin{array}{l}-0.20 \\
* * \\
* *\end{array}$ & - & \\
\hline $\begin{array}{l}\text { 13. W4 peer } \\
\text { rejection- }\end{array}$ & $0.23^{* *}$ & $0.21^{* *}$ & 0.18 & $0.29^{* *}$ & $0.21^{* *}$ & $0.29^{*}$ & $0.21^{*}$ & -0.09 & -0.24 & -0.04 & -0.23 & 0.47 & - \\
\hline
\end{tabular}




\begin{tabular}{|c|c|c|c|c|c|c|c|c|c|c|c|c|c|}
\hline YR & & & & & & & & & ${ }^{* * *}$ & & & & \\
\hline$M$ & 1.42 & 1.37 & 1.31 & 8.78 & 7.34 & 9.48 & 6.79 & 4.14 & 4.13 & 2.78 & 2.79 & 3.34 & 3.40 \\
\hline$S D$ & 0.52 & 0.39 & 0.35 & 6.96 & 5.69 & 8.33 & 4.93 & 0.70 & 0.77 & 0.34 & 0.37 & $\begin{array}{l}0.67 \\
1\end{array}$ & $\begin{array}{l}0.68 \\
7\end{array}$ \\
\hline
\end{tabular}

Notes. $\mathrm{BF}=$ best friend; $\mathrm{FR}=$ father report; $\mathrm{MR}=$ mother report; $\mathrm{PR}=$ parent report; $\mathrm{W} 1=\mathrm{W}$ ave W2=Wave 2; W3=Wave 3; W4=Wave 4; YR=youth report. ${ }^{*}<.05 ;{ }^{* *} p<.01$.

\section{Triangulation and Perceived Peer Relations}

As hypothesized, controlling for marital hostility, triangulation into marital conflict was uniquely associated with lower levels of perceived support from friends/peers and higher levels of perceived peer rejection (Figure 1). The unique association between triangulation and perceived peer support was negative and significant $(\beta=-.46, p<.001)$. The association between triangulation and perceived peer rejection was positive and significant $(\beta=.38, p<.001)$. Model fit was good, $\chi^{2}=26.96(15), p=.029$, CFI=.97, RMSEA=.044. Thus, the first hypothesis for this study that adolescents' triangulation into parents' marital conflict is associated with difficulties in perceived peer relations 2 and 3 years later during the early adolescence period was supported.

Moderating effects of youth gender. The second part of the first hypothesis was that the association between triangulation and peer relations is stronger for daughters than for sons (although significant for both). This part of the hypothesis was tested using SEM with multiple groups. All of the statistical parameters were constrained to equality across the two groups, and the model was estimated. The chi-square from this fully constrained model was compared with the chi-square from a second model in which the structural paths between triangulation and the two latent peer relations constructs were allowed to differ across the two groups. A difference in the two chi-squares indicated that one or both associations was stronger for one group than the other. A nonsignificant change in chi-square indicated that the strength of the associations were not different for daughters and sons.

Contrary to the hypothesis of stronger associations for daughters, there was no difference in the strength of the two associations for daughters and sons $\left(\Delta \chi^{2}=4.45, d f=12, p=.11\right)$. The unstandardized estimates were higher for sons than for daughters, although the difference was not statistically significant. Thus, the deleterious association between youths' triangulation into parents' marital conflict and adolescents' perceived peer relations was not different for daughters and sons.

\section{Adolescent Problem Behaviors as a Mediating Explanation}

The second hypothesis of this study was that the prospective association between triangulation and perceived peer relations would be mediated by adolescent problem behaviors. This hypothesis was supported with regards to the association between triangulation and perceived rejection from peers but not with the regards to the association between triangulation and 
perceived peer support (Figure 2). Controlling for W1 observed marital hostility, W2 adolescent problem behaviors completely mediated the positive association between W1 adolescents' triangulation into parents' marital conflict and adolescents' perception of rejection by peers. The model fit was adequate, $\chi^{2}=91.62(35), \mathrm{CFI}=.92$, $\mathrm{RMSEA}=.062$.

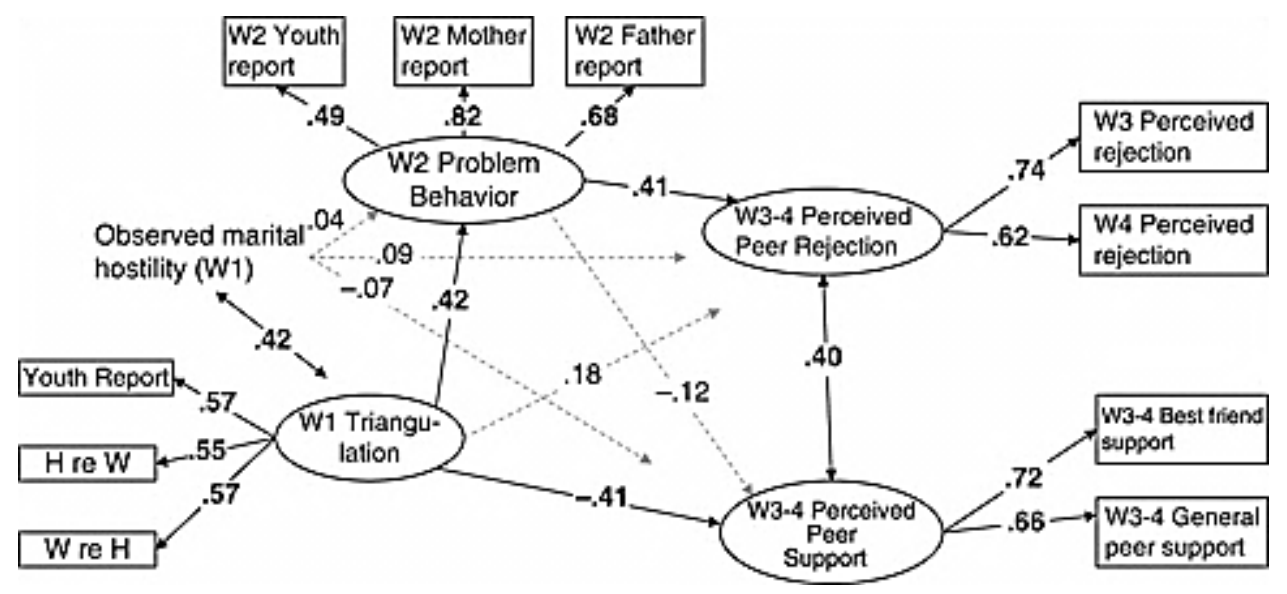

Figure 2. Youths' triangulation in marital conflict and perceived peer relations as mediated by adolescents' problem behaviors.

Follow-up analyses. Additional analyses were conducted to specify the mediating role of adolescents' problem behavior with regards to the prospective association between triangulation and perceived peer rejection. Although no a priori hypotheses were formulated, adolescent externalizing and internalizing problems were analyzed as separate constructs to examine specific pathways. An a priori decision was made to estimate error covariances for internalizing and externalizing problems that were assessed using the same form (e.g., youth report of internalizing and externalizing). This was done because shared method variance was expected when using the Achenbach measures, which include both internalizing and externalizing items within each inventory (Kenny \& Kashy, 1992).

Controlling for the correlation between problem syndromes $(.46, p<.001)$, adolescents' internalizing problems completely mediated the association between youth triangulation in marital conflict and adolescents' perceived peer rejection (Figure 3). The model fit was good, $\chi^{2}=118.84(60), \mathrm{CFI}=.96, \mathrm{RMSEA}=.049$. Adolescents' externalizing problems was not a significant mediator because of a nonsignificant unique association between externalizing problems and perceived peer rejection. Although there was no statistically significant difference in the adequacy of the models presented in Figures 2 and 3 using the chi-square difference test (i.e., $\Delta \chi^{2}=27.22, d f=25, p>.05$ ), the other two fit indices suggested that the model presented in Figure 3 fit the data better than did the model presented in Figure 2. 


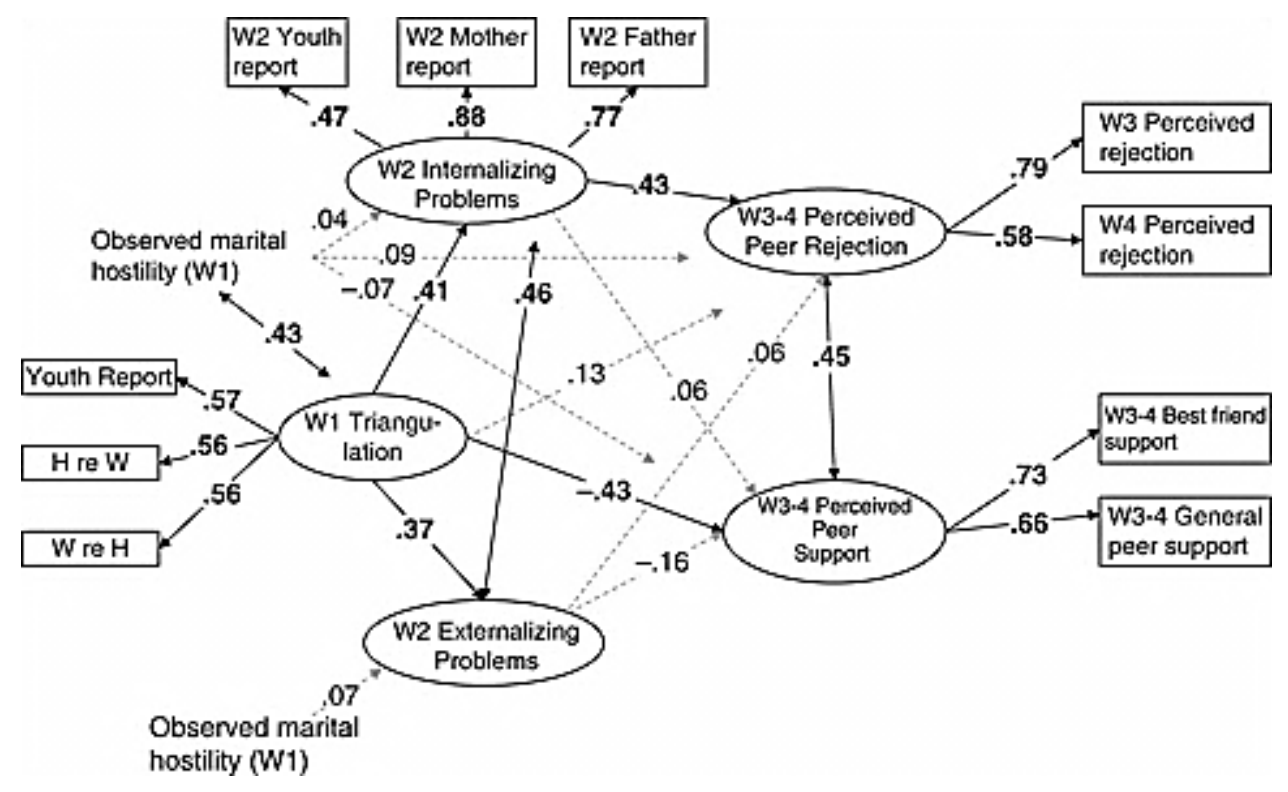

Figure 3. Youths' triangulation in marital conflict and perceived peer relations as mediated by adolescents' externalizing and internalizing problem behaviors.

\section{DISCUSSION}

Triangulation is a systemic process in which conflict or tension that occurs between two people becomes triadic because a third person becomes involved in the situation. This study examined one form of triangulation - early adolescents' triangulation into married parents' disputes. We tested the proposition that youths' triangulation in marital conflict is a risk factor for adolescent's development during the first half of adolescence. We found support for this proposition in that triangulation was associated over time with less perceived support from friends, greater perceived dislike or rejection by peers, higher levels of externalizing problems, and higher levels of internalizing problems. Thus, there is accumulating evidence that youths' triangulation in parents' marital conflict poses risks for socioemotional development during early adolescence. These patterns persisted when controlling for concomitant associations with marital hostility.

Theory offers some direction when considering why triangulation in marital conflict presents risks for adolescents (Kerr \& Bowen, 1988). Triangulation places youth in compromising and confusing positions within the family system. They might be asked to side with one parent against the other, which can create loyalty conflicts (Amato \& Afifi, 2006). Youth also might wish to minimize their involvement in parents' disputes and be placed in a position of having to deny support to a solicitous parent. This is difficult for youth given parental support and acceptance are needed for emotional security. Youth who serve as conflict mediators also are in difficult positions within the family. For example, more powerful spouses might take offense as youth support less powerful partners in their role as mediator. Being a mediator also is difficult when parents' conflicts are chronic because the chances for successful conflict management or resolution are limited. Triangulated youth might begin to feel increasingly more responsible for 
parental conflict that cannot be mediated successfully. These compromising and confusing elements of triangulation are reflected in youths' endorsements of "feeling caught or torn" between parents.

In addition to creating confusion and distress, triangulation into marital conflict exposes youth to parents' negative conflict strategies. As such, youth experience parents having difficulty regulating emotions, parents blaming one another for difficulties, and passive-aggressive conflict tactics such as sarcastic humor and manipulation. These experiences teach youth problematic ways of interacting with intimates that potentially compromise peer relationships (Markiewicz et al., 2001). This is particularly important during early and middle adolescence when building good relationships with friends and peers in general is a central developmental issue (Buhrmester, 1990).

Although theory has suggested that youths' triangulation into marital conflict places them at risk for problems in social relationships, research on triangulation and adolescents' peer relationships is sparse. In the current study, three aspects of adolescents' perceptions of peer relations were examined: perceived support from a best friend and from friends in general, as well as perceived dislike and rejection by peers. We found that triangulation was associated with each of these dimensions of peer relations, suggesting that the risks associated with triangulation are fairly broad based, affecting both friendship qualities and peer status variables. Friendship support and peer status are important aspects of peer relations during early adolescence (Brown \& Klute, 2003), and the linkages with triangulation into marital conflict highlight one of the ways in which boundary violations within families transfer to children's social relationships outside of the family (Parke et al., 2001).

There has been some speculation that daughters are particularly vulnerable to the deleterious effects of triangulation in marital conflict (Jacobvitz \& Bush, 1996). We did not find this. Instead, we found that the association between triangulation and perceived peer relations characterized both sons and daughters. However, future research needs to reconsider gender by examining specific elements of triangulation. For example, triangulation might place sons at risk for relational problems with peers by creating emotional distress (i.e., reactivity) and teaching ineffective emotional regulation strategies. Triangulation might place daughters at risk for future peer problems by reinforcing third-party interventions that manifest later as relational aggression with close friends. Until future research examines more specific mechanisms, however, the results from this study suggest that triangulation in marital conflict is a risk factor for both sons and daughters.

We also examined the proposition that adolescent problem behaviors mediate the association between triangulation and perceived peer relations. Problem behavior, specifically internalizing problems, was a linking mechanism for perceived peer rejection but not for perceived peer support. The linkage was not present for friendship support because of nonsignificant relationships between problem behavior and perceived peer support. Thus, the findings from this 
study suggest that youth with externalizing and internalizing problems have friends they can count on and receive support from when needed (Dishion, Andrews, \& Crosby, 1995; Giordano, Cernkovich, \& Pugh, 1986).

To the contrary, adolescent problem behavior linked triangulation and perceived peer rejection because youth with higher levels of problem behaviors perceived greater dislike and rejection by peers. Some of the emotional distress that accompanies triangulation seems to reduce youths' peer network because problem behaviors were associated with greater perceived dislike and rejection by some peers over time. Previous research has documented that youth with problems behaviors are at risk for rejection by the larger peer group (Cairns, Cairns, Neckerman, \& Gariepy, 1988; Rubin, Coplan, Chen, Buskirk, \& Wojslawowicz, 2005).

Although we had not hypothesized differences regarding internalizing and externalizing problems, follow-up analyses indicated unique pathways. Adolescent internalizing problems completely mediated the association between triangulation in marital conflict and perceived peer rejection. As such, perceived peer status is associated with emotional distress that manifests in depressive affect, anxiety, and withdrawal. This finding is consistent with Bowen's (1978) theorizing regarding the effects of triangulation. He argued that triangulation creates anxiety in the triangulated family member that then impairs close social relationships outside of the family over time. The developmental risks associated with internalized distress during middle adolescence were highlighted by these findings.

An alternative explanation to Bowen's focus on anxiety as a generational transmitter of relational dysfunction is the possibility that youth who have higher levels of externalizing problems, but not internalizing problems, have impaired abilities to perceive accurately their peer status. This potential explanation will need to be addressed in future research that also includes a measure of actual peer rejection before concluding that the association between adolescents' triangulation into marital conflict and peer rejection is not mediated by youths' externalizing problems.

These findings need to be interpreted within the context of several study limitations. The sample included predominately families of European descent. The findings should be generalized to families with other ethnic backgrounds with caution. The study also was limited by its reliance on questionnaire methods and within-family informants. It would have been strengthened by reports of friendship support from close friends, by reports of dislike and rejection from classmates or a broader peer network, and by observations of friendship interactions (Bagwell \& Coie, 2003).

In addition to addressing these study limitations, future research needs to examine specific emotional and cognitive responses associated with triangulation. It is important that patterns of youths' specific thoughts and feelings are identified because these patterns will help identify specific process mechanisms. It also is important to identify specific social behaviors that youth learn when triangulated in marital conflicts. This will increase the understanding of skill sets or 
deficits youth bring to the relationships with close friends and social relationships with peers in general.

The study also could have been strengthened by the inclusion of measures of peer rejection and support at W1. In addition to addressing how triangulation is associated with changes in perceived peer status and support over time, the inclusion of these W1 measures would have helped minimize the possibility that the associations found in the current study are spurious due to the effects of some underlying inherited behavioral or personality trait. The inclusion of adolescent problem behaviors helped address this possibility to some extent but the inclusion of W1 peer measures would have provided additional precision.

In conclusion, the findings from this study support the proposition that triangulation in parental disputes places youth at risk for lower levels of perceived support in friendships and higher levels of perceived rejection over time. As theorized, the deleterious association with perceived peer rejection was mediated by prospective associations with general difficulties in adolescents' socioemotional functioning, specifically internalizing problems such as anxiety, depressive affect, and withdrawal.

\section{ACKNOWLEDGMENTS}

This research was supported by a grant from the National Institute of Mental Health, R01MH59248. We thank the staff of the Family Life Project for their unending contributions to this work and the youth, parents, teachers, and school administrators who made this research possible.

\section{REFERENCES}

Achenbach, T. M. (1991). Manual for the child behavior checklist/4-18 and 1991 profile. Burlington, VT: University of Vermont Department of Psychiatry.

Acock, A. (2005). Working with missing values. Journal of Marriage and Family, 67, 10121028.

Afifi, T. D. (2003). Feeling caught in stepfamilies: Managing boundary turbulence through appropriate communication privacy rules.Journal of Social and Personal Relationships, 20, 729_ 755.

Amato, P. R., \& Afifi, T. D. (2006). Feeling caught between parents: Adult children's relations with parents and subjective well-being.Journal of Marriage and Family, 68, 222-235.

Anderson, S. A., \& Fleming, W. M. (2003). Late adolescents' identity formation: Individuation from the family of origin. Adolescence, 84,785-797. 
Bagwell, C. L., \& Coie, J. D. (2003). The best friendships of aggressive boys: Relationship quality, conflict management, and rule-breaking behavior. Journal of Experimental Child Psychology, 88, 5-24.

Benson, M. J., Larson, J., Wilson, S., \& Demo, D. (1993). Family of origin influences on late adolescent romantic relationships.Journal of Marriage and the Family, 55, 663-672.

Bosco, G. L., Renk, K., Dinger, T. M., Epstein, M. K., \& Phares, V. (2003). The connections between adolescents' perceptions of parents, parental psychological symptoms, and adolescent functioning. Applied Developmental Psychology, 24, 179-200.

Bowen, M. (1978). Family therapy in clinical practice. New York: Jason Aaronson.

Bowen, G., Wooley, M. E., \& Richman, J. M. (2001). Brief intervention in schools: The school success profile. Brief Treatment and Crisis Intervention, 1, 43-54.

Bradford, K., Barber, B. K., Olsen, J. A., Maughan, S. L., Erickson, L. D., Ward, D., et al. (2004). A multi-national study of interparental conflict, parenting, and adolescent functioning: South Africa, Bangladesh, China, India, Bosnia, Germany, Palestine, Colombia, and the United States. Marriage and Family Review, 35, 107-137.

Brown, B. B., \& Klute, C. (2003). Friendships, cliques, and crowds. In G. R.Adams \& M. D.Malden (Eds.), Blackwell handbook of adolescence (pp. 330-348). Malden, MA: Blackwell Publishing.

Browne, M. W., \& Cudeck, R. (1993). Alternative ways of assessing model fit. In K. A.Bollen \& J. S.Long (Eds.), Testing structural equation models (pp. 136-162). Newbury Park, CA: Sage.

Buchanan, C. M., Maccoby, E. E., \& Dornbusch, S. M. (1991). Caught between parents: Adolescents' experience in divorced homes.Child Development, 62, 1008-1029.

Buehler, C., Krishnakumar, A., Stone, G., Anthony, C., Pemberton, S., Gerard, J., et al. (1998). Interparental conflict styles and youth problem behaviors: A two-sample replication study. Journal of Marriage and the Family, 60, 119-132.

Buhrmester, D. (1990). Intimacy of friendship, interpersonal competence, and adjustment during preadolescence and adolescence.Child Development, 61, 1101-1111.

Byrne, B. M. (2001). Structural equation modeling with AMOS: Basic concepts, applications, and programming. Mahwah, NJ: Lawrence Erlbaum Associates.

Cairns, R. B., Cairns, B. D., Neckerman, S. D. G., \& Gariepy, J. (1988). Social networks and aggressive behavior: Peer support or peer rejection? Developmental Psychology, 24, 815-823. 
Cantrell, P. J., MacIntyre, D. I., Sharkey, K. J., \& Thompson, V. (1995). Violence in the marital dyad as a predictor of violence in the peer relationships of older adolescents/young adults. Violence and Victims, 10, 35-41.

Capaldi, D. M., \& Clark, S. (1998). Prospective family predictors of aggression toward female partners for at-risk young men.Developmental Psychology, 34, 1175-1188.

Capaldi, D. M., \& Crosby, L. (1997). Observed and reported psychological and physical aggression in young, at-risk, couples. Social Development, 6, 184-206.

Capaldi, D. M., \& Stoolmiller, M. (1999). Co-occurrence of conduct problems and depressive symptoms in early adolescent boys: III. Prediction to young-adult adjustment. Development and Psychopathology, 11, 59-84.

Charles, R. (2007). Is there any empirical support for Bowen's concepts of differentiation of self? The American Journal of Family Therapy, 29, 279-292.

Conger, R. D., Conger, K. J., \& Elder, G. H. (1992). A family process model of economic hardship and adjustment of early adolescent boys. Child Development, 63, 526-541.

Conger, R. D., Cui, M., Bryant, C. E., \& Elder, G. H. (2000). Competence in early adult romantic relationships: A developmental perspective on family influences. Journal of Personality and Social Psychology, 79, 224-237.

Crick, N. R., \& Grotpeter, J. K. (1995). Relational aggression, gender, and social-psychological adjustment. Child Development, 66,710-722.

Davies, P. T., \& Lindsay, L. L. (2004). Interparental conflict and adolescent adjustment: Why does gender moderate early adolescent vulnerability? Journal of Family Psychology, 18, 160170.

Dishion, T. J., Andrews, D. W., \& Crosby, L. (1995). Antisocial boys and their friends in early adolescence: Relationship characteristics, quality, and interactional process. Child Development, 66, 139-151.

Dishion, T. J., Eddy, M., Haas, E., Li, F., \& Spracklen, K. (1997). Friendships and violent behavior during adolescence. Social Development, 6, 207-223.

Dunn, J., Davies, L., O'Connor, T., \& Sturgess, W. (2001). Family lives and friendships: The perspectives of children in step-, single-parent, and nonstep families. Journal of Family Psychology, 15, 272-287.

Giordano, P. C., Cernkovich, S. A., \& Pugh, M. D. (1986). Friendships and delinquency. American Journal of Sociology, 91,1170-1202. 
Grych, J. H., Raynor, S. R., \& Fosco, G. M. (2004). Family processes that shape the impact of conflict on adolescents. Development and Psychopathology, 16, 649-665.

Grych, J. H., Seid, M., \& Fincham, F. D. (1992). Assessing marital conflict from the child's perspective: The Children's Perception of Interparental Conflict Scale. Child

Development, 63, 558-572.

Hay, D. F., Payne, A., \& Chadwick, A. (2004). Peer relations in childhood. Journal of Child Psychology and Psychiatry, 45, 84-108.

Hu, L. T., \& Bentler, P. M. (1999). Cutoff criteria for fit indexes in covariance structure analysis: Conventional criteria versus new alternatives. Structural Equation Modeling, 6, 1-55.

Hymel, S., Rubin, K. H., Rowden, L., \& LeMare, L. (1990). Children's peer relationships: Longitudinal prediction of internalizing and externalizing problems from middle to late childhood. Child Development, 61, 2004-2021.

Jacobvitz, D. B., \& Bush, N. F. (1996). Reconstruction of family relationships: Parent-child alliances, personal distress, and self-esteem. Developmental Psychology, 32, 732-743.

Kenny, D. A., \& Kashy, D. A. (1992). Analysis of the multitrait-multimethod matrix by confirmatory factor analysis. Psychological Bulletin, 112, 165-172.

Kerig, P. K. (1996). Assessing the links between interparental conflict and child adjustment: The conflicts and problem-solving scales. Journal of Family Psychology, 10, 454-473.

Kerig, P. K. (2001). Children's coping with interparental conflict. In J. H.Grych \& F. D.Fincham (Eds.), Interparental conflict and child development: Theory, research, and application (pp. 213-245). New York: Cambridge University Press.

Kerns, K. A., Contreras, J. M., \& Neal-Barnett, A. M. (2000). Family and peers: Linking two social worlds. Westport, CT: Praeger.

Kerr, E., \& Bowen, M. (1988). Family evaluation: An approach based on Bowen theory. New York: Norton.

Ladd, G. W., \& Burgess, K. B. (1999). Charting the relationship trajectories of aggressive, withdrawn, and aggressive/withdrawn children during early grade school. Child Development, 70, 910-929.

Margolin, G., Gordis, E. B., \& Richard, J. S. (2001). Coparenting: A link between marital conflict and parenting in two-parent families.Journal of Family Psychology, 15, 3-21. 
Markiewicz, D., Doyle, A. B., \& Brengdon, M. (2001). The quality of adolescents' friendships: Associations with mothers' interpersonal relationships, attachment to parents and friends, and prosocial behavior. Journal of Adolescence, 24, 429-445.

Melby, J., \& Conger, R. D. (2001). The Iowa Family Interaction Rating Scales: Instrument summary. In P. K.Kerig \& K. M.Lindall (Eds.),Family observational coding systems: Resources for systemic research (pp. 33-58). Mahwah, NJ: Erlbaum.

Melby, J. N., Conger, R. D., Book, R., Rueter, M., Lucy, L., Repinski, D., et al. (1993). The Iowa family interaction rating scales (4th ed.). Unpublished manuscript, Center for Family Research in Rural Mental Health, Iowa State University, Ames.

Minuchin, S. (1974). Families and family therapy. Cambridge, MA: Harvard University Press.

Newman, D. A. (2003). Longitudinal modeling with randomly and systematically missing data: A simulation of ad hoc, maximum likelihood, and multiple imputation. Organizational Research Methods, 6, 328-362.

O'Neil, R., Parke, R. D., Flyr, M., \& Wild, M. (1999). Marital interaction and children's peer competence. Unpublished manuscript, University of California, Riverside.

Parke, R. D., Kim, M., Flyr, M., McDowell, D. J., Simpkins, S. D., Killian, C. M., et al. (2001). Managing marital conflict: Links with children's peer relationships.

In J.Grych \& F.Fincham (Eds.), Interparental conflict and child development: Theory, research, and application (pp. 291-314). Cambridge, UK: Cambridge University Press.

Parker, J. G., \& Asher, S. R. (1987). Peer relations and later personal adjustment: Are lowaccepted children at risk? Psychological Bulletin, 102, 357-389.

Rubin, K. H., Coplan, R. J., Chen, X., Buskirk, A. A., \& Wojslawowicz, J. C. (2005). Peer relationships in childhood. In M. H.Bornstein \&M. E.Lamb (Eds.), Developmental science: An advanced textbook (pp. 469-512). Mahwah, NJ: Lawrence Erlbaum Associates.

Shadish, W., Cook, T., \& Campbell, D. (2002). Experimental and quasi-experimental designs for generalized causal inference (Chapters 2 \& 3). Boston, MA: Houghton Mifflin Company.

Updegraff, K. A., Helms, H. M., McHale, S. M., Crouter, A. C., Thayer, S. M., \& Sales, L. H. (2004). Who's the boss? Patterns of perceived control in adolescents' friendships. Journal of Youth and Adolescence, 33, 403-421.

U.S. Census Bureau. (2000a). PCT40. Median family income in 1999 (dollars) by family type by presence of own children under 18 years. Retrieved September 3, 2005, from http://factfinder.census.gov, Summary File 3. 
U.S. Census Bureau. (2000b). PCT148A. Sex by educational attainment for the population 25 years and over (white alone). Retrieved September 29, 2004, from http://factfinder.census.gov, Summary File 3.

Vernberg, E. M., Abwender, D. A., Ewell, K. K., \& Beery, S. H. (1992). Social anxiety and peer relationships in early adolescence: A prospective analysis. Journal of Clinical Child Psychology, 21, 189-196.

Wang, L., \& Crane, D. R. (2001). The relationship between marital satisfaction, marital stability, nuclear family triangulation, and childhood depression. The American Journal of Family Therapy, 29, 337-347.

West, J. D., Zarski, J. J., \& Harvill, R. (1986). The influence of the family triangle on intimacy. American Mental Health Counselors Association Journal, 8, 166-174.

Westerman, M. A. (1987). Triangulation, marital discord, and child behavior problems. Journal of Social and Personal Relationships,4, 87-106. 